\title{
Food-rewarded operant learning in the opossum
}

\author{
W. F. ANGERMEIER \\ Universität zu Köln, Köln, Federal Republic of Germany \\ and \\ J. McLEAN, D. MINVIELLE, and C. GRUE \\ University of New Orleans, New Orleans, Louisiana
}

Five 10-month-old wild male opossums (Didelphis virginiana) were used as subjects in a study of food-rewarded operant learning. All animals learned the assigned task. Neither the general slope of the learning curve (measured in terms of intervals between rewarded responses) nor the learning time or number of rewards to criterion differed significantly from data obtained using other mammals. The results are discussed in terms of an evolutionary model of comparative learning.

For decades it was thought that an animal with a primitive brain, such as the opossum, would not be very successful in learning tasks used with other mammals, such as the rat (James, 1984). However, James $(1955,1958$, 1959, 1960), Cone and Cone (1970), James and McFarland (1966), and James and Turner (1963) were able to demonstrate that the opossum can learn virtually all of the tasks presented to it (such as operant conditioning, maze learning, color and object discrimination, etc.) with the exception of double alternation. Although foodrewarded operant learning has been accomplished with the opossum (James, 1984), no detailed analysis of the learning process has been made.

This paper constitutes such an analysis, with respect to number of rewards to criterion, learning time, and interresponse intervals between rewarded responses during the phases of acquisition and performance. Additionally, the results of the present experiment (extinction data included) are compared with those obtained with other vertebrate species.

\section{METHOD}

\section{Subjects}

Five 10-month-old wild male opossums (Didelphis virginiana) were used as subjects. The animals were obtained from a licensed dealer who had trapped them 4 weeks prior to shipping. The animals were housed singly in stainless steel cages $(90 \times 60 \times 60 \mathrm{~cm}$ wide) that contained special nesting boxes ( $30 \times 60 \times 12 \mathrm{~cm}$ high) with soft paper nesting material. Thus, the animals were adapted to laboratory conditions for a period of 30 days, during which they were handled daily and had ad-lib access to commercial dry food and water. Once a week they received their food in the form of processed meat (chicken-based hot dogs).

This research was supported in part by a grant from the Deutsche Forschungsgemeinschaft (DFG), Bonn, Federal Republic of Germany, and the Psychology Department of the University of New Orleans. Requests for reprints should be sent to: W. F. Angermeier, Psychologisches Institut I, Lehrstuhl: Angermeier, Universität zu Köln, Meister-EkkehartStr. 9, 5000 Köln 41, Federal Republic of Germany.

\section{Apparatus}

The apparatus consisted of an operant box $(28 \times 35 \times 45 \mathrm{~cm}$ long) constructed of translucent plastic. Inserted into the bottom of the cage was a floor of sheet metal, which was connected to one pole of a drinkometer device. A rat lever, affixed to one end panel of the box about $7 \mathrm{~cm}$ off the floor, was connected to the other pole of the drinkometer. A rectangular food receptacle $(4 \times 8 \mathrm{~cm}$ wide) was affixed to the panel slightly below and $2 \mathrm{~cm}$ to the right of the lever. Centered on this receptacle was a circular $2.5-\mathrm{cm}$ wide opening in the end panel through which food could be delivered.

\section{Procedure}

After $23 \mathrm{~h}$ of food deprivation, the animals were placed singly into the apparatus. Each response to the lever was reinforced with a small piece of hot dog, weighing approximately $0.3 \mathrm{~g}$, which was approximately $1 / 300$ of the average daily food consumption. Animals were run for $1 \mathrm{~h}$ per day on consecutive days until they had obtained 50 rewards on a continuous reinforcement schedule (CRF). At this time they were removed from the apparatus and returned to their respective home cages.

Three days later they were returned to the apparatus, given 10 pieces of hot dog, and then exposed to extinction for $1 \mathrm{~h}$. All contingencies were programmed automatically by a computer, with the exception of the food delivery, which was accomplished manually.

Each response to the lever and each entry into the food magazine was recorded in terms of hours, minutes, and seconds. These measures were used to obtain number of rewards to criterion, corrected learning time (time between the first rewarded response and reaching the learning criterion), and the learning criterion itself, which consisted of the average number of rewarded responses attained per minute after the response rate had stabilized (Angermeier, 1984). The learning criterion was thus established empirically.

Table 1

Food-Rewarded Operant Learning in the Opossum

\begin{tabular}{lccc}
\hline & $\begin{array}{c}\text { Number of } \\
\text { Rewards to } \\
\text { Criterion }\end{array}$ & $\begin{array}{c}\text { Corrected } \\
\text { Learning Time } \\
\text { (Minutes) }\end{array}$ & $\begin{array}{c}\text { Number of } \\
\text { Responses } \\
\text { During Extinction }\end{array}$ \\
\hline Subject 110 & 14 & 66 & 89 \\
Subject 120 & 25 & 163 & 49 \\
Subject 130 & 17 & 5 & 227 \\
Subject 140 & 15 & 7 & 374 \\
Subject 150 & 16 & 53 & 37 \\
Median & 16 & 53 & 89 \\
Mean & 17.4 & 58.8 & 155.2 \\
SD & 4.4 & 64.3 & 143.8 \\
\hline
\end{tabular}


The data also permitted the construction of a learning curve and an extinction curve, and therefore made possible a meaningful comparison between the opossum's behavior and the behavior of other mammals from which data were obtained in an identical fashion.

\section{RESULTS}

All five animals learned the required behavior, as one can see from Table 1 . The data show that the subjects needed a median of 16 rewarded responses to reach the learning criterion. This criterion varied from 4-6 rewarded responses per minute, depending upon the performance of the individual animal. Median corrected learning time was $53 \mathrm{~min}$. The number of responses emitted during extinction varied from 37 to 374 . There are two interesting trends in these data: a high positive correlation ( $(82)$ between number of responses to criterion and corrected learning time, and a negative correlation (-.71) between corrected learning time and number of responses during extinction. Neither correlation was, however, significant, a fact that is probably due to the small number of animals used.

Figure 1 shows the opossum's position relative to other mammals tested with respect to number of rewards to criterion (Angermeier, 1984). The data show that in a food-rewarded simple operant learning task the opossum behaves like all the other mammals tested. It is also evident that lower species need fewer rewards to criterion than do more highly evolved animals.

Figure 2 contains the learning curves constructed for four mammals: the rat, the rabbit, the raccoon, and the opossum. Here, too, it is evident that the opossum does not differ significantly from the other mammals.

Figure 3 shows cumulative curves of extinction for the rat and for the opossum. In both cases the animals had previously received 50 rewards on a CRF schedule. Again, there appears to be little difference between these extinction functions, except that the curve for the opossums is somewhat more irregular than that for the rats.

\section{DISCUSSION}

Zoologists consider the opossum to be of "pivotal importance" in comparative behavior studies (Eisenberg, 1981). This is no less true for psychologists interested in comparative learning abilities. In contrast to approaches of other investigators, such as Harlow and Mears (1979) and Bitterman (1975), our own approach attempts to compare various classes of vertebrates (i.e., fishes, reptiles, birds, and mammals) on a relatively simple task for food reward. In such a situation the opossum, as one of the oldest living mammals, is especially interesting, because its behavior can be compared to that of species evolved much later. The opossum is generally believed to have originated more than 63 million years ago (Eisenberg, 1981), which would make this animal at least 10 times as old as man. Yet all observations and measurements made in this study show that the opossum's food-rewarded operant learning capability does not differ significantly from that of other mammals tested so far (mice, rats, rabbits, raccoons, and human infants).

When one compares the behavior of the different species, it becomes evident that simple operant learning ability does not appear to have evolved any more with growing encephalization. Once a certain brain weight/body weight ratio was reached, the approximate number of rewards necessary to ensure stable responding (see Figure 1) was the same within the various classes of organisms tested (i.e., fishes, birds, mammals). Although increasing encephalization within the clusters shown is apparently responsible for more complex behavioral repertoires and the mastery of increasingly difficult tasks, it seems to have no effect on simple operant learning.

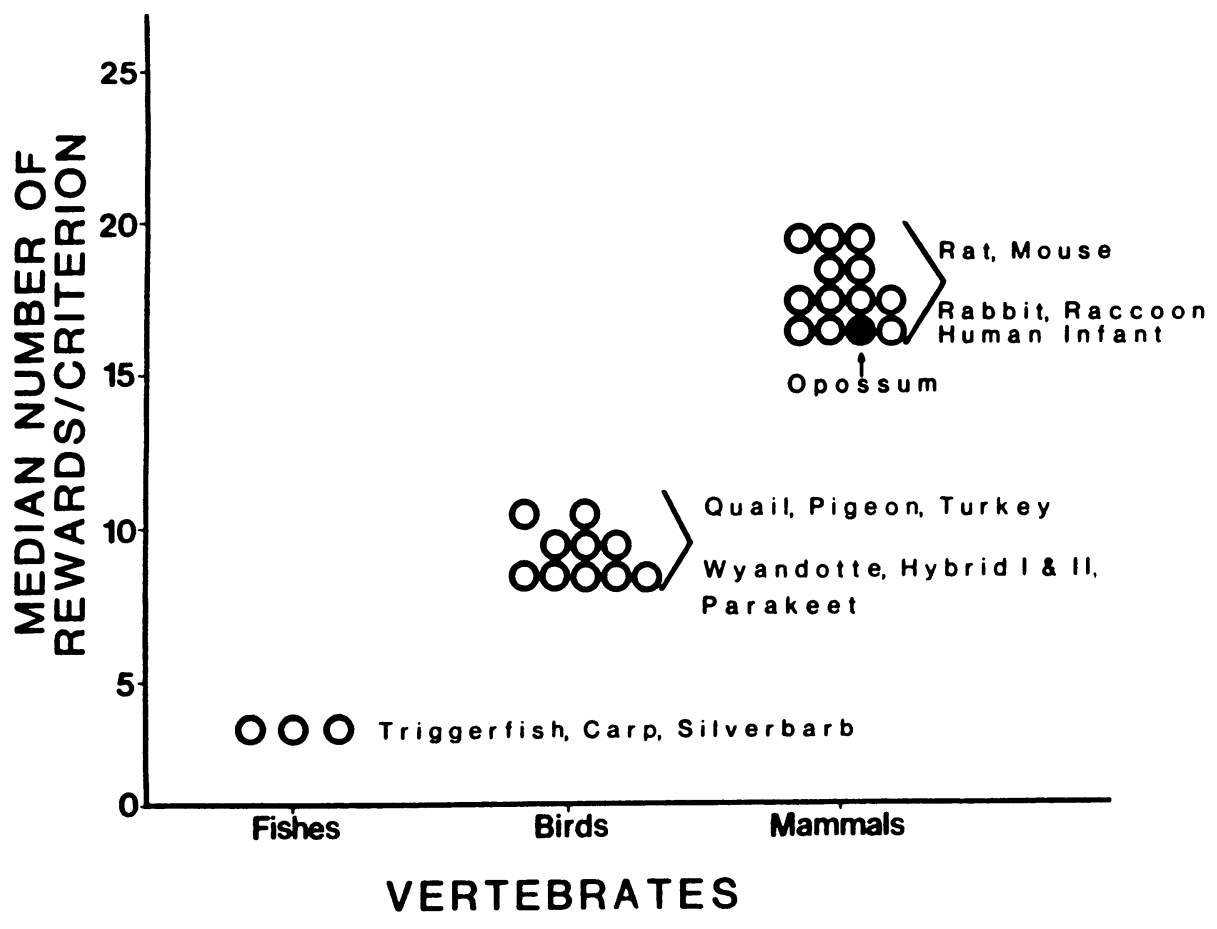

Figure 2. Comparison of the opossum's learning curve with those of the rat, the rabbit, and the raccoon. 


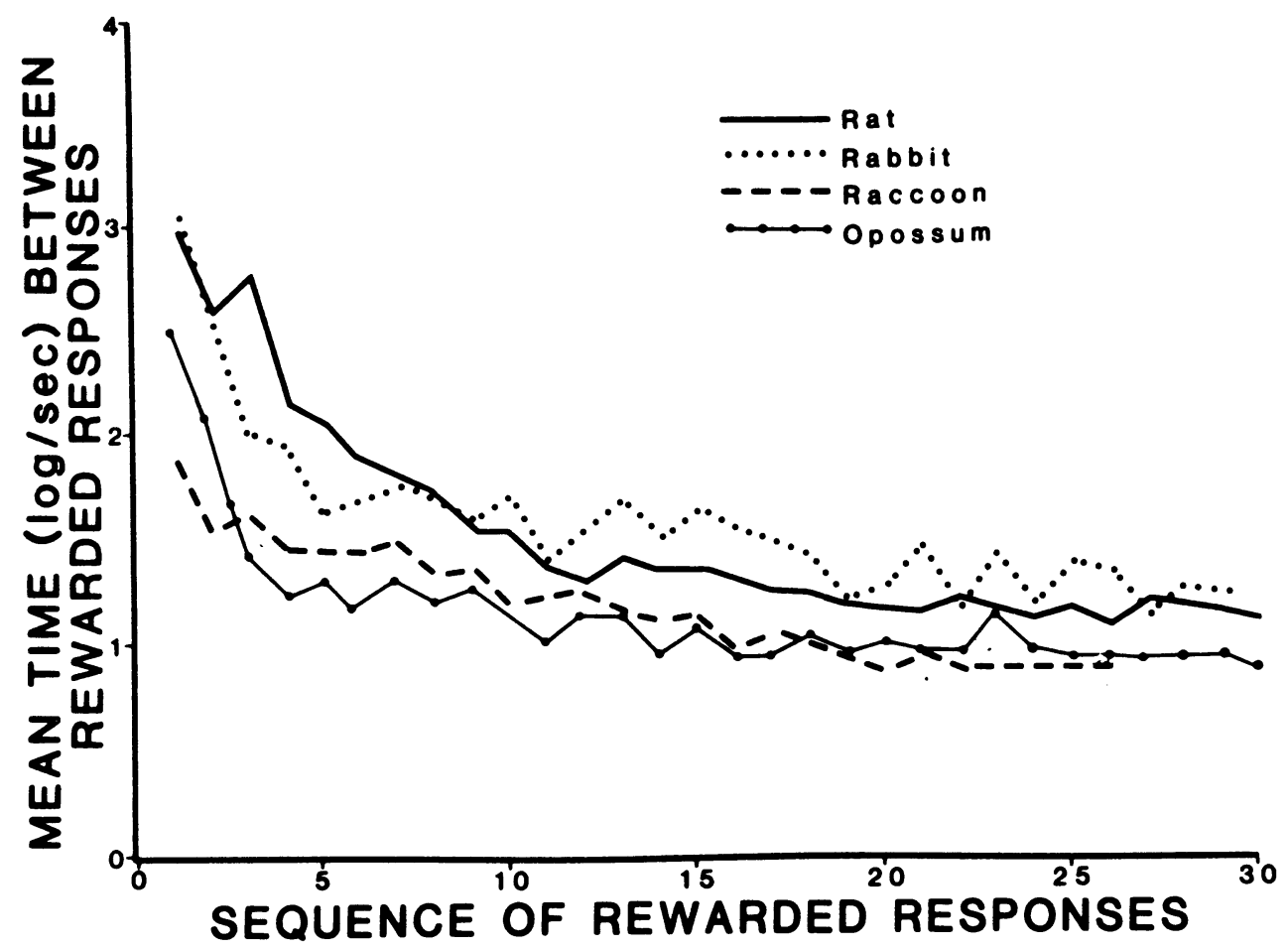

Figure 2. Comparison of the opossum's learning curve with those of the rat, the rabbit, and the raccoon.

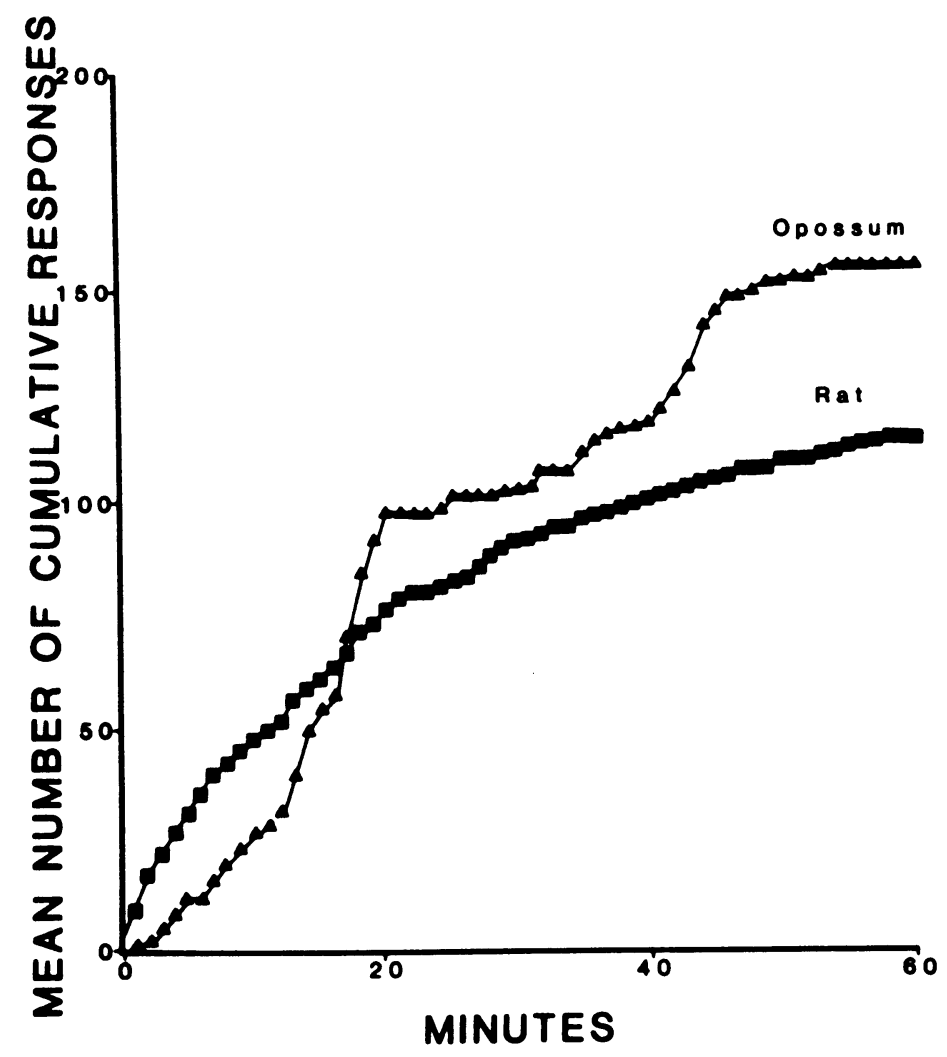

Figure 3. Cumulative extinction curves for the opossum and the Wistar rat. 
This thinking makes sense when one considers the nature and importance of operant learning. Food-getting behaviors rank high in the hierarchy of survival behaviors. It is therefore important that such behaviors be rather strictly genetically determined in lower organisms, which lack the neural complexity responsible for greatly varied behavioral repertoires. No such strict determination is necessary for animals with behavioral repertoires that contain many categories, which assures success in foraging and the procurement of food. A complex cortex can actually be a handicap when the animal has to eliminate many behavioral approaches that happen to be irrelevant in a certain situation, such as simple food-rewarded operant learning. In this case, only one response will lead to success, that is, food, and hence survival.

Finally, one must also consider other hypotheses in explaining the differences between mammals, birds, and fishes, such as the degree of distractibility, which is much larger in more highly evolved organisms. Another idea pertains to the ratio of genetically fixed versus more flexible behavior patterns. Again, this ratio favors the lower organisms in very simple tasks and the more highly evolved species in more complex tasks (Jerison, 1973; Razran, 1971). It appears that all of the factors mentioned here, and probably many more that are not known at this time, contribute to the evolution of simple operant learning, in which the opossum, indeed, occupies a place of pivotal importance.

\section{REFERENCES}

ANGermeIER, W. F. (1984). The evolution of operant learning and memory. New York: Karger.

Bitterman, M. E. (1975). The comparative analysis of learning. Science, 188, 699-709.
Cone, A. L., \& Cone, D. M. (1970). Operant conditioning in the Virginia opossum. Psychological Reports, 26, 83-86.

EISENBERG, J. F. (1981). The mammalian radiations. Chicago: The University of Chicago Press.

HarLow, H. F., \& MeARs, C. (1979). The human model: Primate perspectives. New York: Wiley.

JAMES, W. T. (1955). The behavior of the opossum in the Guthrie-Horton puzzle box. Journal of Genetic Psychology, 87, 203-206.

JAMES, W. T. (1958). Conditioned responses in the opossum. Journal of Genetic Psychology, 93, 179-183.

JAMES, W. T. (1959). Behavior of the opossum in the Fink arrow maze. Journal of Genetic Psychology, 94, 199-203.

JAMES, W. T. (1960). A study of visual discrimination in the opossum. Journal of Genetic Psychology, 97, 127-130.

JAMES, W. T. (1984). An experimental analysis of learning in the opossum. The Journal of General Psychology, 111, 131-152.

JAMES, W. T., \& McFARLAND, J. (1966). A study of form discrimination in the opossum. Journal of Psychology, 64, 193-198.

JAMES, W. T., \& TURNER, W. W. (1963). III. Experimental study of maze learning in young opossums. Psychological Reports, 13, 921-922. JERISON, H. (1973). Evolution of the brain and intelligence. New York: Academic Press.

Razran, G. (1971). Mind in evolution. Boston: Houghton-Mifflin.

(Manuscript received for publication September 12, 1986.) 